\title{
Ley-Farming and a Long-Term Agricultural Policy*
}

\author{
By Prof. R. G. Stapledon, C.B.E.
}

$\mathrm{I}^{\mathrm{N}}$ view of the immense amount that has been published during the present century, it is not without significance that the leading agricultural journals contain but few articles dealing primarily, or even remotely, with the rotation, and next to nothing relative to the basal philosophy of the rotation. The truth is that agricultural thought in recent decades has turned ever more exclusively towards the narrow, too narrow as I think, path of commodities, each considered as such. Excessive concentration on commodities leads inevitably towards monoculture, and to what we too lightly please to call specialization, and leads away from the rotation and ultimately to disaster. Greatly daring, then, I have set myself to combat this modern fetish of over-concentration on commodities.

Such is the precarious state of the world to-day, and of Great Britain in particular, that there can be only one approach to the problems of agriculture, and that is the national approach. It so happens, at least it appears to me, that the present needs of the State, and also the more menacing of the foreseeable contingencies, unite to demand one and the same essential contribution from our agriculture. It is not for me to attempt to decide whether war danger, or the danger of our aboutrapidly-to-dwindle population is the greater peril ; little less disconcerting are the effects of soil erosion and soil depletion in those countries from which we are wont to obtain abundant and cheap supplies of food. I am concerned with a long-term agricultural policy, the kind of policy that would take at least ten years to put into full operation, and consequently we have to consider not so much immediate war danger as such, a danger that owing to our island position would seem to be something from which it is now difficult to see how we shall ever escape. I believe the extent of the influences of soil erosion and depletion are not even yet fully realized. All methods of countering this must in the last resort react against the British housewife, and must tend to increase the cost of overseas production, while taking soil erosion, soil depletion and land deterioration together, a vaster area of the globe is undoubtedly affected than is generally supposed.

The immediate, and on all hands generally admitted, need of our peoples is an abundance of fresh food. An abundance of fresh food is not compatible with a superabundance of permanent

* From the presidential address to Section M (Agriculture) of the British Association delivered at Cambridge on August 19. grass. Since permanent grass flows like the sea right up to the very doors of some of our largest centres of population, such centres of population are automatically denied an abundance of really fresh vegetables.

To sum up so far, and on the strength of the various considerations I have brought forward, I would say this. What is demanded of our agriculture is, first, to maintain as large a rural population as possible, for probably on a large and contented rural population depends to a marked degree the increase of our population as a whole; secondly, to maintain as large an acreage as possible in a highly fertile and always ploughable condition ; and thirdly, so to conduct our farming as to allow at all times, and in all places, for the absolute maximum of flexibility in commodity production.

Four systems of farming, namely, arable, leyfarming, nondescript and permanent grass, account for most of the farms of Great Britain. Unless we know the number of farms and the gross acreage of such farms operating on each of these systems, we know next to nothing as to how Great Britain stands relative to potential food production. Furthermore, schemes for helping the farmer via commodity subsidization and by planned market. ing cannot be assessed in their influence on the maintenance and enhancement of soil fertilityand that is what matters above all things-unless we know the systems of farming under which the assisted commodities are being predominantly produced. How much quota wheat, for example, is being produced respectively on arable farms, nondescript farms, or on ley farms? Where is most of the milk being produced-and this is a matter of fundamental national importance in the interest alike of the health of the cattle and of the children of this country-on nondescript farms, permanent grass farms, or on ley farms? Where is most of the permanent grass of the country ; and where is the best and where the worst-on nondescript farms, or on permanent grass farms ? These are all essential facts to be known in the formulation of a long-term national policy for agriculture. The facts are only on the land; the agricultural statistics cannot give anything approaching a full answer to any one of these questions.

The answer to these questions, and to equally important questions connected with facilities at the farmstead and over the fields (watering, drainage, and the condition of fences), can only be given by a properly conducted survey carried 
out over the whole country and on a uniform plan. Map also the type or class of all the rough grazings and permanent grass (in a manner broadly similar to the survey of Wales recently undertaken by my department), and map the ploughability of the several fields: then, and only then, should we know where we stand. To conduct such a survey would be a relatively simple matter. To my mind, until such a survey is put in hand, and the lessons of the same-cruel and bitter the lessons will beduly digested, there is little hope that the country at large will realize either the deplorable condition of our acres or their immense potentialities. The first necessity from all points of view-that of the statesman, the townsman, farmer and countryman, in short, that of the nation-is literally and in fact to put rural Britain on the map.

Only when rural Britain is on the map shall we be able, amongst other matters, to decide where in the national interest it is desirable to extend arable farming, and where ley-farming, and where it may be necessary or permissible to tolerate nondescript and permanent grass farming.

In my view no problems so much as those of grassland demand prolonged and large-scale agronomical investigation. I would wish to distinguish between, on one hand, agronomical research, and on the other, scientific research as normally understood and conducted. The major aim of agronomical research, which is essentially field research, is to study all the factors which are operative at once and together, and in their natural interplay, for "nature is a theatre for the inter-relations of activities". Such a procedure, it may be said, is impossible, or at least unscientific. It is certainly not impossible, and if it is unscientific it will yet remain agronomical, and many of the problems of agriculture are more likely to be solved, shall I say, by agronomical investigation than by scientific research, while nearly all the results of scientific research have to pass through the sieve of an immense amount of agronomical investigation before they can be made useful, and in some cases perhaps before they can be other than positively dangerous to the practitioner.

The technique of agronomical research entails a great deal more than blindly following all the elaborate rules and regulations laid down by the statisticians; indeed, such rules and regulations are of no fundamental significance in the proper planning of an elaborate series of field experiments. They are sometimes, but by no means always, useful in the actual placing of plots on the ground, and they are sometimes essential, but are by no means always necessary, in the examination of quantitative data. One effect of the modern glorification of statistical methods has undoubtedly been a tendency to obscure the wood by the trees, to concentrate on the part, often an isolated part (yield, for example), instead of the whole; and, worse still, to fill the agronomist with a medley of complexes and inhibitions which have reacted adversely on the development of a technique adequate to solve a large number of the problems that can only be solved by highly complicated field experiments. Many agronomists are almost too frightened to set up the sort of experiments their experiences teach should be set up, because they are timorous lest the data could be made amenable to statistical analyses.

Agriculture would have been the gainer if the agronomist had never been taught to be timorous, and if he had plodded away undeterred and undismayed at the details of his own technique, when by now perhaps he would have been able to justify his claim that what is primarily wanted to-day is enormously increased facilities for the conduct of field experiments, in contradistinction to field trials and demonstrations. That at least is my claim, for I claim to be an agronomist, and in that capacity one who has been responsible for the setting up of hundreds of weird little field experiments involving, in all, literally thousands of plots.

As always, however, the greatest and the final hope is the farmer himself, for he at least is untrammelled by the technique of science, and is not a slave to the fashions current in science, while his major training is not in collecting data, but in the gentle art of unzdulterated observation. Just because, therefore, of the immense accumulation of scientific knowledge, so much of it but half digested in the practical sphere, there has never been so urgent a necessity as at present for an abundance of well-informed, originally minded and affluent pioneers, men willing and eager to transgress against every eanon of good husbandry, and to explore, and almost de novo, the whole field of rotation of crops, and the whole idea of rotation of pastures of different types and of stock over the surface of the farm.

I have adopted an unusual course in my approach to my subject; instead of reviewing the data and evidence available, I have in effect reviewed my own reactions to the implications of the work with which I have been connected for the past twenty-five years and more. Perhaps I need not apologize for this, for after all, facts and data are of no practical use until people grapple with the practical implications. Instead of my 'facts'-and scientific 'facts' are not always correct-I have put my grapplings before you, that is all, and if justification is necessary, I think sufficient justification is the admittedly deplorable conditions of a huge acreage of Great Britain, the dilapidated condition of many of our farms and farmsteads, and the therefore necessarily backward state of 
much of our farming. Two needs seem to me to be crystal clear : first, the conduct of a survey on the land-and I believe every agricultural scientist, though perhaps not every farmer and every economist, would agree to 'on the land' somewhat on the lines I have suggested-and then the ways and means of getting the plough into the grasslands that the survey conclusively proves ought to be ripped up. Working capital, and the correct expenditure of that working capital, is in the last resort the only solution for our derelict and quasi-derelict acres.

I like the American idea of loans with a working plan; of loans with advice. I do not believe that the history of the years since about 1894 shows that the spasmodic periods of agricultural prosperity that have on occasion intervened have been responsible for a great deal of land improvement, or for a proportionate improvement in the equipment necessary for productive farming. Prosperity as such in agriculture, as in industry, is to a large degree a function of equipment, for without the necessary equipment it is impossible to farm economically, just as it is impossible to manufacture economically.

Again, it is unreasonable to expect that a man devoid of working capital, and probably the son of a man similarly devoid, should have all the knowledge of how best to farm, and particularly of how best to improve land (in which art he will necessarily have had no sort of experience), in sympathy with adequate working capital suddenly provided for the purpose. Advice, and some measure of control, must necessarily go with credit facilities, and in so far as breaking up grassland is concerned I like still better the American idea of group loans, and of a 'master borrower'. The 'master borrower' in this case would be set up as a contractor with tractor and necessary equipment to break up the grasslands, for it is important to remember that ploughing up of this sort is essentially tractor work, that it interferes with the normal routine of an ill-equipped farm, while tractors are to all intents and purposes nonexistent in many of the districts where wholesale ploughing up is most necessary. My own experiences are interesting in this connexion. We tested the desire for contracting last year, and had three times as many applications as we could fit into the acreage we could do, while now, and because of the demand our work has created locally, a lorry contractor in the neighbouring village has acquired a tractor, and is fully engaged on contract ploughing.

I like also the American idea of being boldly eclectic and scheduling particular districts as being eligible for their rehabilitation loans. There are innumerable districts that should be similarly scheduled and similarly helped in Great Britain, but always through financial help cum technical advice terminating in an agreed working plan; and here again my own experience comes to support my contention, for in those cases where we contracted, we only did so when the farmer agreed to follow all our advice as to subsequent operations, manures and seeds, to the letter, and in all cases the farmer has done so, and demonstrably to his own advantage.

The breaking up of derelict grassland is to be helped forward not only by loans, but by a reorientation of such working capital as the farming community possesses, and also, I think, by a reorientation of the monetary and other arrangements existing between landlord and tenant.

Ley-farming in my view affords great scope for such re-orientation, for it would make possible, and on a general scale, a variety of methods of share farming. For example, one might conceive of a mechanized wheat grower operating over a large number of neighbouring ley farms on a share basis ; c nother man on a share basis might be running the poultry, the proprietors themselves being primarily interested in the adequacy of the rotation and farming operations, and possibly in one major product-milk, shall we say? By this means farmers should achieve a better return on such working capital as is available, and also the nation should achieve a more balanced specialization between farming qua farming and commodity production and disposal. Landlords themselves could often think out with advantage methods of sharingin with their tenants, and ley-farming opens many avenues of approach to such sharing-in; but in any event it behoves the landlords of many districts to be alive to changing times, and to be ready for the day-not, I think, far distant-when better tenants will be found for farms which are going concerns on the ley-farming basis than for those which are nondescript or permanent grass. It may thus prove to be a wise policy to adjust leases, and even financially to assist purposeful tenants towards that system of farming which will accord best with the trend of national and international events.

Let me insist, in conclusion, that the affairs of agriculture, slowly moving as they necessarily must be, are ill-adapted to respond to the dictates of any immediate expediency, for expediency is ever shifting, and at the best "is the mere shadow of what is right and true". To be ever prepared for change in a world that is ever changing can be the only possible basis for a sound agricultural policy for Great Britain, since we are so peculiarly liable to be crucially affected by happenings beyond our own control, beyond our own jurisdiction and beyond our own borders. 